\title{
Adsorption of hexavalent chromium onto activated carbon derived from Leucaena leucocephala waste sawdust: kinetics, equilibrium and thermodynamics
}

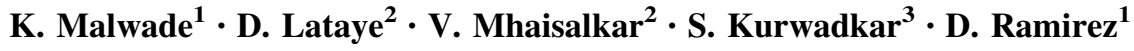

Received: 9 February 2016/Revised: 25 May 2016/Accepted: 23 June 2016/Published online: 7 July 2016

(C) Islamic Azad University (IAU) 2016

\begin{abstract}
The adsorptive removal of $\mathrm{Cr}(\mathrm{VI})$ was studied using activated carbon derived from Leucaena leucocephala (ACLL). The physico-chemical properties of ACLL were determined using proximate analysis and $\mathrm{N}_{2}$ BET surface area analysis. The $\mathrm{N}_{2}$ BET surface area of ACLL was determined to be $1131 \mathrm{~m}^{2} \mathrm{~g}^{-1}$. The point of zero charge $\left(\mathrm{pH}_{\mathrm{pzc}}\right)$ of 5.42 indicated that ACLL surface was positively charged for $\mathrm{pH}$ below the $\mathrm{pH}_{\mathrm{PZC}}$, attracting anions. The effect of experimental operating parameters such as time of contact, ACLL dose, $\mathrm{pH}$, initial concentration and temperature was investigated. The optimum values of parameters such as concentration of $100 \mathrm{mg} \mathrm{L}^{-1}$, $300 \mathrm{mg}$ of ACLL dose, time of contact of $60 \mathrm{~min}, \mathrm{pH}$ of 4 indicated the maximum $\mathrm{Cr}(\mathrm{VI})$ uptake of $13.85 \mathrm{mg} \mathrm{g}^{-1}$. The pseudo-second-order kinetic model best fitted with the $\mathrm{Cr}(\mathrm{VI})$ adsorption data. Adsorptive removal of $\mathrm{Cr}(\mathrm{VI})$ onto ACLL satisfactorily fitted in the order of Redlich-Peterson $>$ Freundlich $>$ Langmuir $>$ Temkin adsorption isotherm model. The thermodynamic parameters showed the adsorption of $\mathrm{Cr}(\mathrm{VI})$ onto ACLL was an endothermic and spontaneously occurred process.
\end{abstract}

Keywords Adsorption - Cr(VI) - ACLL · Kinetics · Isotherms · Thermodynamics

S. Kurwadkar

skurwadkar@fullerton.edu

1 Department of Environmental Engineering, Texas A\&M University-Kingsville, Kingsville, TX 78363, USA

2 Department of Civil Engineering, Visvesvaraya National Institute of Technology Nagpur, Nagpur 440010, India

3 Department of Civil and Environmental Engineering, California State University, 800 N. State College Blvd., Fullerton, CA 92834, USA

\section{Introduction}

$\mathrm{Cr}(\mathrm{VI})$ is one of the most commonly occurring toxic pollutants in the environment. Occurrence of $\mathrm{Cr}(\mathrm{VI})$ is a human health and ecological concern due to its toxicity, mutagenicity and carcinogenicity (Belay 2010; Huang et al. 2012). Due to its high solubility in water, $\mathrm{Cr}(\mathrm{VI})$ is readily available for biological uptake. It is also more toxic compared to $\mathrm{Cr}(\mathrm{III})$ (Jing et al. 2011). $\mathrm{Cr}(\mathrm{VI})$ is also a strong oxidizing agent and can cause severe damage to cell membranes (Belay 2010).

Environmental occurrence of $\mathrm{Cr}(\mathrm{VI})$ is almost entirely attributed to anthropogenic activities (USEPA 2010). Some of the major sources of occurrence of $\mathrm{Cr}(\mathrm{VI})$ in the environment is the unregulated wastewater discharge originating from industrial processes such as metal plating, manufacture of pigments and dyes, corrosion inhibitors, chemical synthesis, refractory production, leather tanning and wood preservation (Vinodhini and Das 2009; Wang et al. 2009).

Exposure to $\mathrm{Cr}(\mathrm{VI})$ can have severe human health consequences. For example, researchers have documented that exposure to $\mathrm{Cr}(\mathrm{VI})$ can cause long-term and serious public health hazards such as skin irritation, lung cancer, as well as kidney, liver and gastric damage (Qaiser et al. 2009; Vinodhini and Das 2009). Cr(VI) also poses significant ecological risk. For example, in the case of plants, $\mathrm{Cr}(\mathrm{VI})$ can severely affect the mitotic process and reduces seed germination in extensively cultivated pulse crops (Belay 2010).

Some of the commonly used methods for removal of $\mathrm{Cr}(\mathrm{VI})$ are chemical reduction, precipitation, reverse osmosis, ion exchange and electro-coagulation (Rao et al. 2007; Deng et al. 2009). These Cr(VI) removal methods result into the formation of toxic sludge that requires further disposal. Furthermore, these removal processes cannot be used efficiently for low or high concentrations and 
require costly chemical and physical operations with involvement of high degree of maintenance and supervision (Srivastava and Goyal 2010).

In this study, a relatively sustainable approach is developed to investigate adsorptive removal of $\mathrm{Cr}(\mathrm{VI})$. A laboratory-developed novel adsorbent material prepared from L. leucocephala waste sawdust was studied for the adsorptive removal of $\mathrm{Cr}(\mathrm{VI})$ from aqueous phase. To better understand the removal mechanism of this unique adsorbent material, extensive adsorption experiments were conducted and the data were analysed using various sorption kinetics, sorption isotherms and thermodynamics.

\section{Materials and methods}

\section{Materials}

Sawdust of Leucaena leucocephala was procured from local wood processing industry. Analytical grade $\mathrm{K}_{2} \mathrm{Cr}_{2} \mathrm{O}_{7}$ (CAS \# 7778-50-9) was purchased from MERCK Chemicals.

\section{Adsorbent preparation}

The raw sawdust of L. leucocephala was sieved to obtain a uniform particle size of $250 \mu \mathrm{m}$. The sieved sawdust was washed with de-ionized water until all the dust, residual oils and other impurities were completely removed. The washed sawdust was sun-dried for about $24 \mathrm{~h}$ and kept in oven at $105{ }^{\circ} \mathrm{C}$ temperature for about $1 \mathrm{~h}$. The dried sawdust was mixed with ortho-phosphoric acid in the 1:1 ratio (mg of sawdust/mL of phosphoric acid) to impregnate the mixture for $24 \mathrm{~h}$. The impregnated mixture was kept in air tight container and combusted in the furnace at $400{ }^{\circ} \mathrm{C}$ for $1 \mathrm{~h}$. The formed activated carbon was washed with deionized water until the acid was completely removed. The washed activated carbon was dried in oven at $105^{\circ} \mathrm{C}$ for $24 \mathrm{~h}$. This laboratory manufactured activated carbon from L. leucocephala (ACLL) was then used for conducting series of adsorption experiments.

\section{Adsorbate preparation}

A $\mathrm{Cr}(\mathrm{VI})$ stock solution of $1000 \mathrm{mg} \mathrm{L}^{-1}$ was prepared by mixing $2.827 \mathrm{~g}$ of $\mathrm{K}_{2} \mathrm{Cr}_{2} \mathrm{O}_{7}$ in $1 \mathrm{~L}$ of de-ionized water. This stock solution was serially diluted to get the appropriate concentrations for conducting adsorption experiments.

\section{Physico-chemical properties of ACLL}

The specific surface area of the ACLL was measured using a high-speed surface area and pore size analyser (NOVA
2200, Quantachrome) with $\mathrm{N}_{2}$ and the Brunauer-EmmettTeller (BET) method. The proximate analysis of ACLL was carried out using the standard procedure from IS 1350 (Part I):1984. The surface morphology of ACLL was analysed using JEOL JSM-6400F FESEM (Field Emission Scanning Electron Microscopy).

\section{Determination of point of zero charge $\left(\mathrm{pH}_{\mathrm{pzc}}\right)$ of ACLL}

The $\mathrm{pH}_{\mathrm{pzc}}$ of ACLL was determined by the $\mathrm{pH}$ titration (Órfão et al. 2006). The $25 \mathrm{~mL}$ volume of $0.01 \mathrm{M} \mathrm{KNO}_{3}$ solution was taken in six different Erlenmeyer flasks. The $\mathrm{pH}$ of the solution was adjusted by adding $0.1 \mathrm{M} \mathrm{NaOH}$ and $0.1 \mathrm{M} \mathrm{HCl}$ solutions. $25 \mathrm{mg}$ of ACLL was added in each flask. The suspension of ACLL in each flask was agitated, and the final $\mathrm{pH}$ of each sample was noted after $48 \mathrm{~h}$. The difference in the initial and final $\mathrm{pH}$ of the solution was obtained. Finally, the plot between $\mathrm{pH}_{\mathrm{i}}$ versus $\left(\mathrm{pH}_{\mathrm{i}}-\mathrm{pH}_{\mathrm{f}}\right)$ was generated. The point at which the curve of $\mathrm{pH}_{\mathrm{i}}$ versus $\left(\mathrm{pH}_{\mathrm{i}}-\mathrm{pH}_{\mathrm{f}}\right)$ crosses $x$-axis was defined as point of zero charge $\left(\mathrm{pH}_{\mathrm{pzc}}\right)$.

\section{Adsorption experiments}

The adsorption experiments were carried out by mixing ACLL dosage ranging from 100 to $400 \mathrm{mg}$ with $50 \mathrm{~mL}$ of $\mathrm{Cr}$ (VI) test solution in 100-mL Erlenmeyer flasks. The mixture was agitated at the shaking rate of $150 \mathrm{rpm}$ and temperature range of $10-50{ }^{\circ} \mathrm{C}$ by placing in the temperature-controlled orbital shaker (CIS-24 BL) from Remi Instruments, Mumbai. The $\mathrm{pH}$ of $\mathrm{Cr}(\mathrm{VI})$ test solution was adjusted with $0.1 \mathrm{~N} \mathrm{HCl}$ or $0.1 \mathrm{~N} \mathrm{NaOH}$ solution and recorded using digital $\mathrm{pH}$ meter from Systronics $\mu \mathrm{pH}$ system. The standard solutions of 1, 2, 3, 4 and $5 \mathrm{mg} \mathrm{L}^{-1}$ were used to obtain calibration curve. The test samples were analysed on atomic absorption spectrophotometer (AA6300, SHIMADZU) at the wavelength of $358.08 \mathrm{~nm}$.

\section{Calculations}

The percent $\mathrm{Cr}(\mathrm{VI})$ removal and equilibrium adsorption capacity, $q_{\mathrm{e}}\left(\mathrm{mg} \mathrm{g}^{-1}\right)$, were determined by using the following relations:

$\%$ Removal $=\frac{\left(C_{0}-C_{\mathrm{e}}\right)}{C_{0}} \times 100$

$\mathrm{q}_{\mathrm{e}}=\frac{\left(C_{0}-C_{\mathrm{e}}\right) \times V}{m}$

\section{Sorption kinetic and equilibrium isotherm models}

Sorption kinetics of $\mathrm{Cr}(\mathrm{VI})$ onto the ACLL has been analysed using various equilibrium isotherm models. 
Table 1 Sorption kinetic and equilibrium isotherm models used to compare sorption of Cr(VI) onto ACLL

\begin{tabular}{|c|c|c|}
\hline \multicolumn{3}{|l|}{ Kinetic models } \\
\hline First order & $\log \left(q_{\mathrm{e}}-q\right)=\log \left(q_{\mathrm{e}}\right)-\frac{k_{\mathrm{f}}}{2.303} \cdot t$ & \multirow{3}{*}{$\begin{array}{l}\text { Hamadi et al. (2001), Karthikeyan et al. (2005), Malkoc and Nuhoglu (2007), } \\
\text { Bayramoğlu and Yakup Arica (2008) }\end{array}$} \\
\hline Second order & $\frac{t}{q}=\frac{1}{k_{\mathrm{s}} q_{\mathrm{e}}^{2}}+\frac{1}{q_{\mathrm{e}}} \cdot t$ & \\
\hline Elovich & $q_{t}=\frac{1}{\beta} \ln (\alpha \cdot \beta)+\frac{1}{\beta} \ln (t)$ & \\
\hline \multicolumn{3}{|c|}{ Equilibrium isotherm models } \\
\hline Langmuir & $\frac{C_{\mathrm{e}}}{q_{\mathrm{e}}}=\frac{C_{\mathrm{e}}}{q_{\mathrm{m}}}+\frac{1}{K_{\mathrm{L}} \cdot q_{\mathrm{m}}}$ & \multirow[t]{4}{*}{ Kobya (2004), Goswami and Ghosh (2006), Tan et al. (2009) } \\
\hline Freundlich & $\ln \left(q_{\mathrm{e}}\right)=\ln \left(K_{\mathrm{F}}\right)+\frac{1}{n} \cdot \ln \left(c_{\mathrm{e}}\right)$ & \\
\hline Temkin & $q_{\mathrm{e}}=B_{1} \ln \left(K_{\mathrm{T}}\right)+B_{1} \ln \left(C_{\mathrm{e}}\right)$ & \\
\hline Redlich-Peterson & $\ln \left(K_{\mathrm{R}} \frac{C_{\mathrm{e}}}{q_{\mathrm{e}}}-1\right)=\ln \left(a_{\mathrm{R}}\right)+\beta \cdot \ln \left(C_{\mathrm{e}}\right)$ & \\
\hline
\end{tabular}

Table 1 provides the list of kinetic and equilibrium isotherm models that were used to compare the sorption of Cr(VI) onto ACLL. The kinetics of adsorption designates the rate of uptake of adsorbate onto adsorbent and controls the equilibrium time (Karthikeyan et al. 2005). The kinetic study is also important to evaluate adsorption as a unit operation (Bayramoğlu and Yakup Arica 2008).

The mechanism of adsorptive removal of $\mathrm{Cr}(\mathrm{VI})$ using ACLL can be studied and evaluated by obtaining characteristic constants of sorption of $\mathrm{Cr}(\mathrm{VI})$ using first-order and second-order kinetic models. Elovich equation was successfully applied to describe an aqueous-phase adsorption of Cr(VI) onto ACLL (Chen et al. 2010).

The establishment of the most appropriate equilibrium correlation is important to optimize the design of adsorption system (Tan et al. 2009, Malwade et al. 2015). Therefore, four different sorption isotherms were applied to obtain the most appropriate isotherm to compare the experimental data of $\mathrm{Cr}(\mathrm{VI})$ adsorption onto ACLL.

\section{Results and discussion}

\section{ACLL characterization}

Table 2 shows the ACLL physico-chemical properties which are important to know before the adsorption process and enhance adsorption uptake by ACLL. Pores of ACLL can be occupied with moisture content, ash or volatile matter at the room temperature before application and reduce the uptake by ACLL (Malwade et al. 2015).

\section{Point of zero charge $\left(\mathrm{pH}_{\mathrm{pzc}}\right)$}

The point of zero charge $\left(\mathrm{pH}_{\mathrm{pzc}}\right)$ of adsorbent is the $\mathrm{pH}$ of adsorbent suspension at which its surface has a net charge of zero (Kubilay et al. 2007). If the recorded pH of solution is lower than $\mathrm{pH}_{\mathrm{pzc}}$, the adsorbent surface will be
Table 2 Physico-chemical properties of ACLL

\begin{tabular}{ll}
\hline Properties & ACLL \\
\hline $\mathrm{N}_{2}$-BET surface area $\left(\mathrm{m}^{2} \mathrm{~g}^{-1}\right)$ & 1131 \\
Moisture content $(\%)$ & 6.73 \\
Ash content $(\%)$ & 5.56 \\
Volatile matter (\%) & 16.47 \\
Fixed carbon $(\%)$ & 71.24 \\
\hline
\end{tabular}

protonated by the competition of $\mathrm{H}^{+}$ions; On the other hand, if the recorded $\mathrm{pH}$ of solution is higher than $\mathrm{pH}_{\mathrm{pzc}}$, the surface charge will be deprotonated by $\mathrm{OH}^{-}$ions present in the solution (Putra et al. 2009). The plot for $\mathrm{pH}_{\mathrm{pzc}}$ as depicted in Fig. 1 observed $\mathrm{pH}_{\mathrm{pzc}}$ of ACLL value of 5.42.

\section{Scanning electron microscopy (SEM)}

SEM analysis of ACLL was carried out to study the surface morphology pre- and post-adsorption experiments. The ACLL samples were analysed at $1500 \times$ magnification to observe the difference in the surface morphology of virgin ACLL and spent ACLL samples. Figure 2a shows the plain and smooth pores of virgin ACLL that was before adsorption process. Figure $2 b$, on the other hand, shows the distortion of pore spaces, filled voids and scale-like deposition on the surface of ACLL clearly demonstrated the adsorption of $\mathrm{Cr}(\mathrm{VI})$

\section{Operating parameters}

\section{Contact time}

Figure 3 shows an effect of contact time of ACLL in the test solution. It is evidenced from Fig. 3 that there was a significant increase in adsorptive removal of $\mathrm{Cr}(\mathrm{VI})$ onto ACLL up to $30 \mathrm{~min}$. The time of $30 \mathrm{~min}$ recorded $54 \%$ increase in the uptake of $\mathrm{Cr}(\mathrm{VI})$ onto ACLL in comparison 


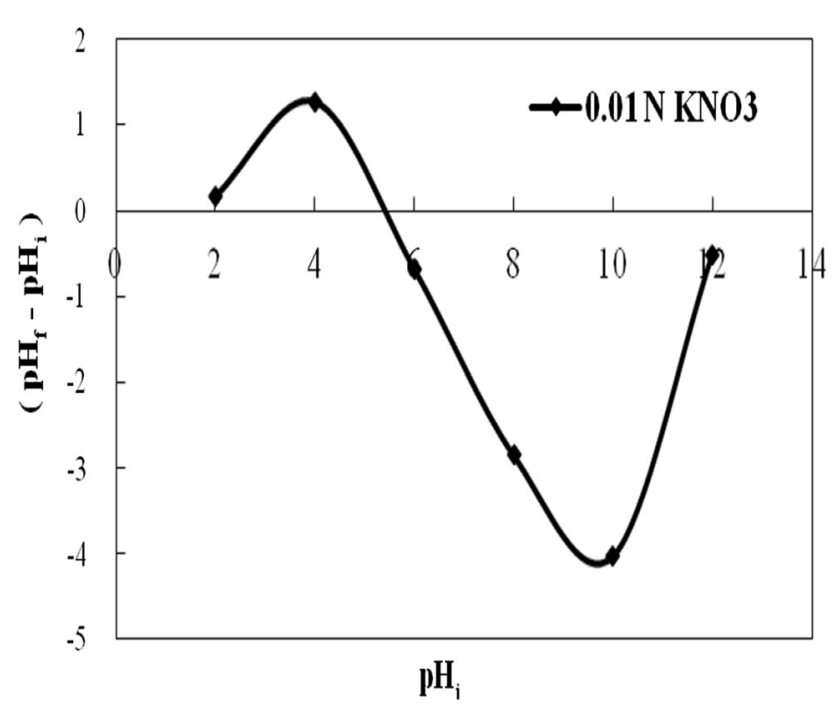

Fig. 1 Point of zero charge for ACLL

with initial 2 min of the adsorption process. However, after 30 min the uptake of $\mathrm{Cr}(\mathrm{VI})$ by ACLL slowed down significantly and recorded an increase of $0.90 \%$ up to $60 \mathrm{~min}$ of time. The highest uptake of $13.85 \mathrm{mg}$ of $\mathrm{Cr}(\mathrm{VI}) / \mathrm{g}$ of ACLL was observed. Adsorption of $\mathrm{Cr}(\mathrm{VI})$ was remained relatively same beyond $30 \mathrm{~min}$, indicating the adsorption process was reached at equilibrium. To be conservative, a contact time of $60 \mathrm{~min}$ was assumed as an equilibrium time.

\section{Effect of ACLL dose}

The adsorptive removal of $\mathrm{Cr}(\mathrm{VI})$ was studied at initial concentration of $100 \mathrm{mg} \mathrm{L}^{-1}$, $\mathrm{pH}$ of 4 , equilibrium time of $1 \mathrm{~h}$, temperature of $30^{\circ} \mathrm{C}$, RPM of 150 and varying the dosage from 100 to $400 \mathrm{mg}$ per $50 \mathrm{~mL}$ of test solution as shown in Fig. 3b. The $\mathrm{Cr}(\mathrm{VI})$ percent removal increases with the increase in dosage because of availability of ample unoccupied sites (Rao et al. 2007; Tailor et al. 2012). It lasts until ACLL reached equilibrium by $\mathrm{Cr}(\mathrm{VI})$, and thereafter uptake attains constant value. The percent $\mathrm{Cr}(\mathrm{VI})$ removal increased because of concentration gradient which reduced mass transfer resistance between $\mathrm{Cr}(\mathrm{VI})$ and ACLL. From Fig. 3b, it was reported that the percent $\mathrm{Cr}(\mathrm{VI})$ removal increased by $29 \%$ with the increase in the adsorbent dose from 100 to $300 \mathrm{mg}$. However, no significant percent removal was observed beyond $300 \mathrm{mg}$ of ACLL. For the sake of generalization, we assumed the adsorbent dose of $300 \mathrm{mg}$ per $50 \mathrm{ml}$ as an optimum dose for the removal of $\mathrm{Cr}(\mathrm{VI})$.

\section{Effect of $p H$}

The effect of $\mathrm{pH}$ was studied at concentration of $100 \mathrm{mg} \mathrm{L}^{-1}, 300 \mathrm{mg}$ of ACLL and $1 \mathrm{~h}$ of equilibrium time as plotted in Fig. 3c. The pH dependence of metal adsorption can largely be related to the type and ionic state of the functional groups as well as the metal chemistry of the test solution (Namasivayam and Yamuna 1995). The effect of $\mathrm{pH}$ on adsorption of $\mathrm{Cr}(\mathrm{VI})$ using ACLL is shown in Fig. 3c. The pH of test solution was considered in the range of 2 to 12 . It was clearly indicated from Fig. $3 \mathrm{c}$ that the $\mathrm{Cr}(\mathrm{VI})$ uptake rapidly decreased from 13.98 to $4.66 \mathrm{mg} \mathrm{g}^{-1}$ beyond $\mathrm{pH}$ 5. The reason behind the decrease in adsorption capacity of $\mathrm{Cr}(\mathrm{VI})$ was abundance of $\mathrm{OH}^{-}$ions in the test solution causing deprotonation of ACLL surface. It means above $\mathrm{pH} 6$, the ACLL surface was negatively charged and caused the decrease in uptake of $\mathrm{Cr}(\mathrm{VI})$. Below $\mathrm{pH}$ 6, adsorption of $\mathrm{Cr}(\mathrm{VI})$ was dominated by negatively charged metal ions being attracted to positively charge
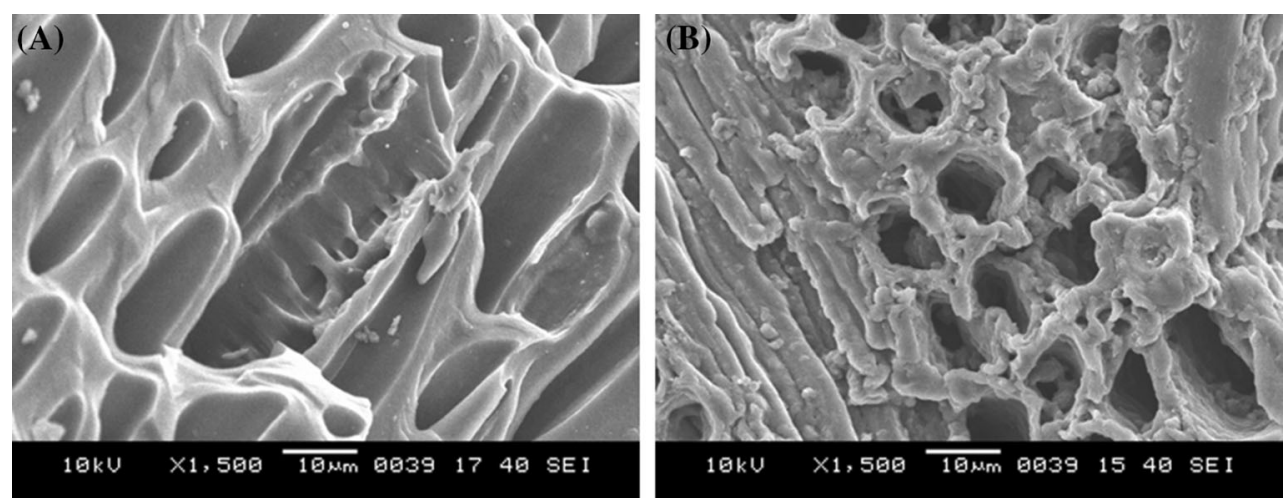

Fig. 2 Surface morphology of a virgin ACLL sample and b spent ACLL sample 
Fig. 3 a Adsorption capacity of ACLL, $\mathbf{b}$ effect of ACLL dosage, $\mathbf{c}$ effect of $\mathrm{pH}, \mathbf{d}$ effect of initial concentration and temperature
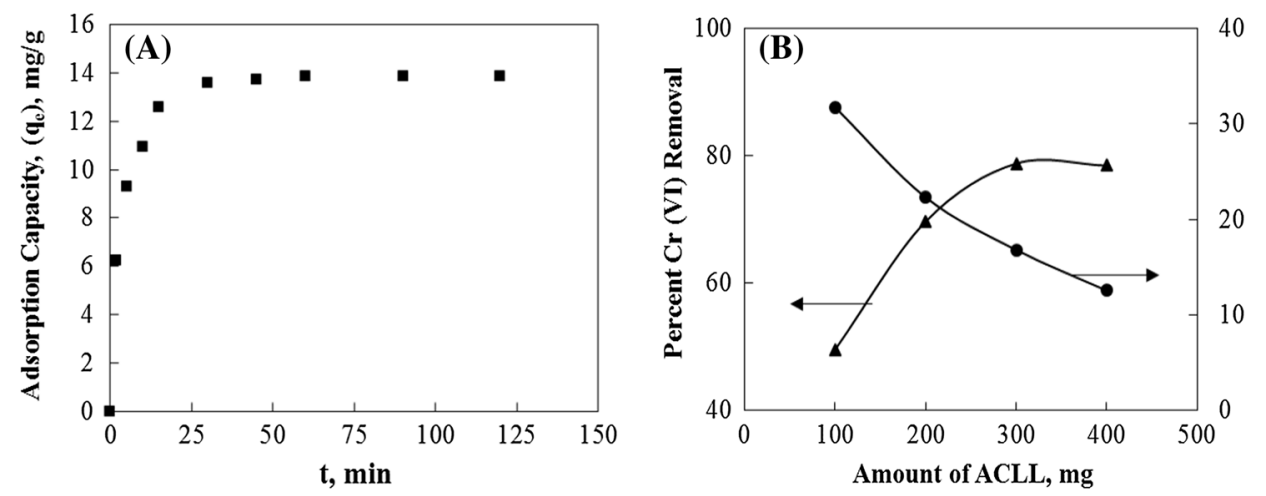

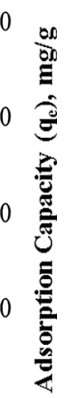
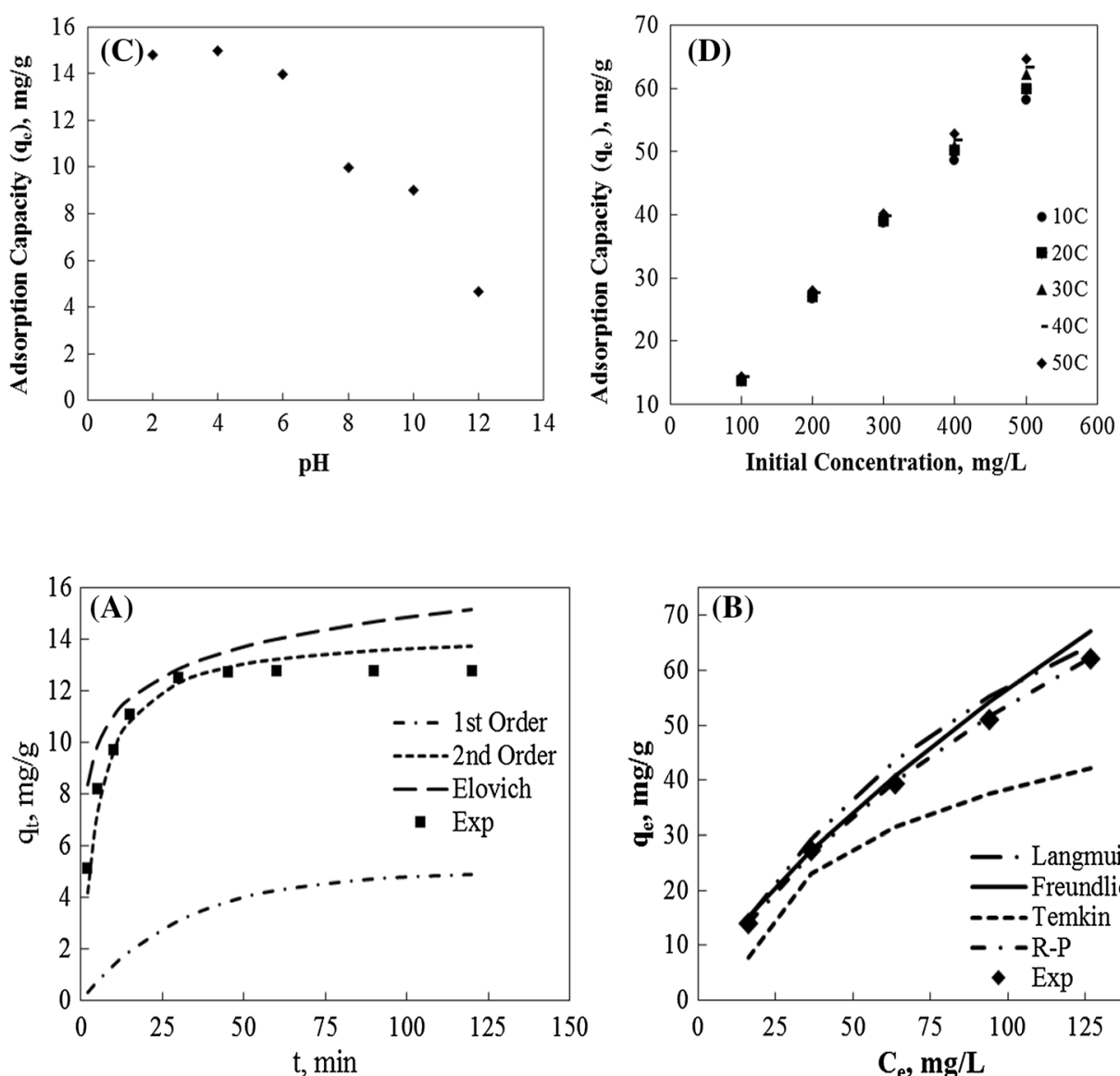

Fig. 4 a Sorption kinetics and b equilibrium isotherm models for adsorption of $\mathrm{Cr}(\mathrm{VI})$ onto ACLL surface sites of ACLL due to electrostatic forces developed between ACLL and test solution. The maximum $\mathrm{Cr}(\mathrm{VI})$ uptake of $14.96 \mathrm{mg} \mathrm{g}^{-1}$ was observed at $\mathrm{pH} 4$, which considered as an optimum $\mathrm{pH}$ value.

\section{Initial concentration $\left(C_{0}\right)$ and temperature}

The initial concentration of $\mathrm{Cr}(\mathrm{VI})$ and temperature had a prominent effect on adsorption of $\mathrm{Cr}(\mathrm{VI})$ on ACLL. Figure $3 \mathrm{~d}$ shows the effect of initial concentration on adsorption of $\mathrm{Cr}(\mathrm{VI})$ onto the ACLL at the temperature range of $10-50{ }^{\circ} \mathrm{C}$. It was observed that adsorption capacity of ACLL increased with an increase in initial concentration of test solution and temperature. This enhanced adsorption capacity could be attributed to the increased mobility of the $\mathrm{Cr}(\mathrm{VI})$ ions due to increase in temperature and the weakening of retarding forces acting on the diffusing ions. Consequently, the concentration gradient helped to increase mass transfer driving force and resulted in increased adsorption capacity of ACLL (Lataye et al. 2008). 
Table 3 Kinetic parameters for adsorption of $\mathrm{Cr}(\mathrm{VI})$ onto ACLL

\begin{tabular}{llll}
\hline First order & $k_{\mathrm{f}}\left(\mathrm{min}^{-1}\right)$ & $q_{\mathrm{e}, \mathrm{cal}}\left(\mathrm{mg} \mathrm{g}^{-1}\right)$ & $R^{2}$ \\
& 0.03 & 4.67 & 0.95 \\
Second order & $k_{\mathrm{s}}\left(\mathrm{g} \mathrm{mg}^{-1} \mathrm{~min}^{-1}\right)$ & $q_{\mathrm{e}, \mathrm{cal}}\left(\mathrm{mg} \mathrm{g}^{-1}\right)$ & $R^{2}$ \\
& 0.01 & 14.29 & 0.99 \\
Elovich & $\alpha\left(\mathrm{mg} \mathrm{g}^{-1} \mathrm{~min}^{-1}\right)$ & $\beta\left(\mathrm{g} \mathrm{mg}^{-1}\right)$ & $R^{2}$ \\
& 126.47 & 0.6 & 0.84 \\
\hline
\end{tabular}

\section{Sorption kinetics and equilibrium isotherm models}

In order to study adsorption kinetics, pseudo-first-order, pseudo-second-order and Elovich equations were used to fit the experimental data as shown in Fig. 4a. Kinetic parameters such as $k_{\mathrm{f}}, k_{\mathrm{s}}, q_{\mathrm{e}, \mathrm{cal}} \alpha, \beta$ and $R^{2}$ as listed in Table 3 were obtained from the slope and intercept of the straight-line plots not shown here (Wang et al. 2006; Atalay et al. 2009; Mohammod et al. 2011; MontazerRahmati et al. 2011).

Table 3 demonstrates that correlation coefficient of second-order kinetic model was very close to unity in comparison with first-order and Elovich kinetic models. Therefore, pseudo-second-order kinetic model provided a good agreement for sorption of $\mathrm{Cr}(\mathrm{VI})$ onto ACLL.

The Freundlich, Langmuir, Temkin and RedlichPeterson isotherm models applied to validate the experimental data of adsorption of $\mathrm{Cr}(\mathrm{VI})$ onto ACLL at temperature of $303^{\circ} \mathrm{K}$ are shown in Fig. $4 \mathrm{~b}$. The equilibrium sorption isotherm parameters along with linear correlation coefficients listed in Table 4 were analysed from slope and intercept of each linear plot of applied isotherm (not shown). Figure $4 \mathrm{~b}$ indicates that the sequence of closely spaced adsorption equilibrium models with adsorption of $\mathrm{Cr}(\mathrm{VI})$ was Redlich-Peterson $>$ Freundlich $>$ Langmuir $>$ Temkin isotherm.

The sum of square error for Redlich-Peterson isotherm model was also witnessed lowest value of 1.03 as mentioned in Table 4. Therefore, Redlich-Peterson isotherm model closely approximated with the experimental data of adsorption of $\mathrm{Cr}(\mathrm{VI})$ onto ACLL than other sorption isotherms.

\section{Estimation of thermodynamic parameters}

The change in reaction that can be expected during adsorption process requires the knowledge of thermodynamic parameters, and the concept of thermodynamic assumes that in an isolated system where energy cannot be gained or lost, the entropy change is the driving force (Kumar and Kumaran 2005; Tan et al. 2009).

The standard free energy change $\left(\Delta G_{\text {ad }}^{\circ}\right)$ for adsorption of $\operatorname{Cr}(\mathrm{VI})$, a function of heat of adsorption $\left(\Delta H^{\circ}\right)$, change in entropy $\Delta S^{\circ}$, and temperature and also related to equilibrium constant $\left(K_{\mathrm{ad}}\right)$ for that process, can be represented by the following equations (Kumar and Kumaran 2005)

Table 4 Sorption isotherm parameters and sum of square error

\begin{tabular}{|c|c|c|c|c|c|c|c|}
\hline \multirow[t]{2}{*}{ Isotherms } & \multirow{2}{*}{ Parameters } & \multicolumn{5}{|c|}{ Temperature (K) } & \multirow{2}{*}{$\begin{array}{l}\text { Sum of square } \\
\text { error at } 303 \mathrm{~K}\end{array}$} \\
\hline & & 283 & 293 & 303 & 313 & 323 & \\
\hline \multirow[t]{3}{*}{ Langmuir } & $K_{\mathrm{L}}\left(\mathrm{L} \mathrm{mg}^{-1}\right)$ & 0.010 & 0.009 & 0.008 & 0.007 & 0.006 & \multirow[t]{3}{*}{48.67} \\
\hline & $q_{\mathrm{m}}\left(\mathrm{mg} \mathrm{g}^{-1}\right)$ & 111 & 125 & 125 & 143 & 143 & \\
\hline & $R^{2}$ & 0.994 & 0.997 & 0.989 & 0.979 & 0.956 & \\
\hline \multirow[t]{3}{*}{ Freundlich } & $K_{\mathrm{F}}\left(\mathrm{L} \mathrm{mg}^{-1}\right)$ & 1.95 & 1.89 & 2.05 & 2.02 & 2.21 & \multirow[t]{3}{*}{39.18} \\
\hline & $n$ & 1.45 & 1.40 & 1.39 & 1.39 & 1.40 & \\
\hline & $R^{2}$ & 0.984 & 0.989 & 0.996 & 0.997 & 0.997 & \\
\hline \multirow[t]{3}{*}{ Temkin } & $K_{\mathrm{T}}\left(\mathrm{L} \mathrm{mg} g^{-1}\right)$ & 0.10 & 0.10 & 0.10 & 0.11 & 0.12 & \multirow[t]{3}{*}{700.10} \\
\hline & $B$ & 21.18 & 22.36 & 22.95 & 23.23 & 23.48 & \\
\hline & $R^{2}$ & 0.992 & 0.988 & 0.973 & 0.967 & 0.958 & \\
\hline \multirow[t]{4}{*}{ Redlich-Peterson } & $a_{\mathrm{R}}\left(\mathrm{L} \mathrm{mg}^{-1}\right)$ & 0.22 & 0.13 & 0.06 & 0.02 & 0.00 & \multirow[t]{4}{*}{1.03} \\
\hline & $K_{\mathrm{R}}\left(\mathrm{L} \mathrm{mg}^{-1}\right)$ & 1.50 & 1.30 & 1.20 & 1.10 & 1.08 & \\
\hline & $\beta$ & 0.50 & 0.54 & 0.65 & 0.85 & 1.38 & \\
\hline & $R^{2}$ & 0.947 & 0.964 & 0.994 & 0.993 & 0.953 & \\
\hline
\end{tabular}


Table 5 Thermodynamic parameters for an adsorption $\mathrm{Cr}(\mathrm{VI})$ using ACLL

\begin{tabular}{llll}
\hline $\begin{array}{l}\text { Temperature } \\
(\mathrm{K})\end{array}$ & $\begin{array}{l}\Delta H^{\circ} \\
\left(\mathrm{kJ} \mathrm{mol}^{-1}\right)\end{array}$ & $\begin{array}{l}\Delta S^{\circ} \\
\left(\mathrm{kJ} \mathrm{mol}^{-1} \mathrm{~K}^{-1}\right)\end{array}$ & $\begin{array}{l}\Delta G^{\circ} \\
\left(\mathrm{kJ} \mathrm{mol}^{-1}\right)\end{array}$ \\
\hline 283 & 3.95 & 0.07 & -16.08 \\
293 & & & -16.79 \\
303 & & & -17.50 \\
313 & & & -18.20 \\
323 & & & -18.91 \\
\hline
\end{tabular}

$\Delta G_{\text {ad }}^{\circ}=\Delta H^{\circ}-T \Delta S^{\circ}$

$\Delta G_{\text {ad }}^{\circ}=-R \cdot T \ln \left(K_{\text {ad }}\right)$

Therefore, Van't Hoff equation can be rewritten as:

$\ln \left(K_{\mathrm{ad}}\right)=-\frac{\Delta G_{\mathrm{ad}}^{\circ}}{R \cdot T}=-\frac{\Delta H^{\circ}}{R \cdot T}+\frac{\Delta S^{\circ}}{R}$

Thus, $\Delta H^{\circ}$ can be calculated by the slope of linear Van't Hoff plot between $\ln \left(K_{\text {ad }}\right)$ and $\frac{1}{T}$.

$\Delta H^{\circ}$ value shown in Table 5 corresponds to zero uptake of $\mathrm{Cr}(\mathrm{VI})\left(q_{\mathrm{e}}=0 \mathrm{mg} \mathrm{g}^{-1}\right)$ by ACLL (Suzuki 1990; Lataye et al. 2008). However, the isosteric heat of adsorption $\left(\Delta H_{\mathrm{st}}\right)$ at assumed surface uptake $\left(q_{\mathrm{e}}\right)$ of $\mathrm{Cr}(\mathrm{VI})$ onto ACLL was obtained using slope of adsorption isosteres and is shown in Fig. 5b, c. Figure 5a indicates that the slope $\left(\Delta H^{\circ}\right)$ of the Van't Hoff equation was negative, meaning adsorption of $\mathrm{Cr}(\mathrm{VI})$ using ACLL was an overall endothermic process. $\Delta S^{\circ}$ provides the state of adsorption during the process. The positive value of $\Delta S^{\circ}$ and negative value of $\Delta G_{\text {ad }}^{\circ}$ indicated that the process occurred spontaneously.

\section{Conclusion}

ACLL manufactured from a waste sawdust of L. leucocephala could be used as environmentally sustainable adsorbent with low moisture, little ash content and smoke. The adsorptive removal of $\mathrm{Cr}(\mathrm{VI})$ using activated carbon derived from a waste L. leucocephala sawdust (ACLL) demonstrates that ACLL has a potential to be a sustainable adsorbent for the removal of $\mathrm{Cr}(\mathrm{VI})$. This observation is supported by the SEM analysis of the of virgin and used ACLL material. According to our
Fig. 5 a Van't Hoff, b sorption isosteres, $\mathbf{c}$ isosteric heat of adsorption of adsorption of $\mathrm{Cr}(\mathrm{VI})$ onto ACLL
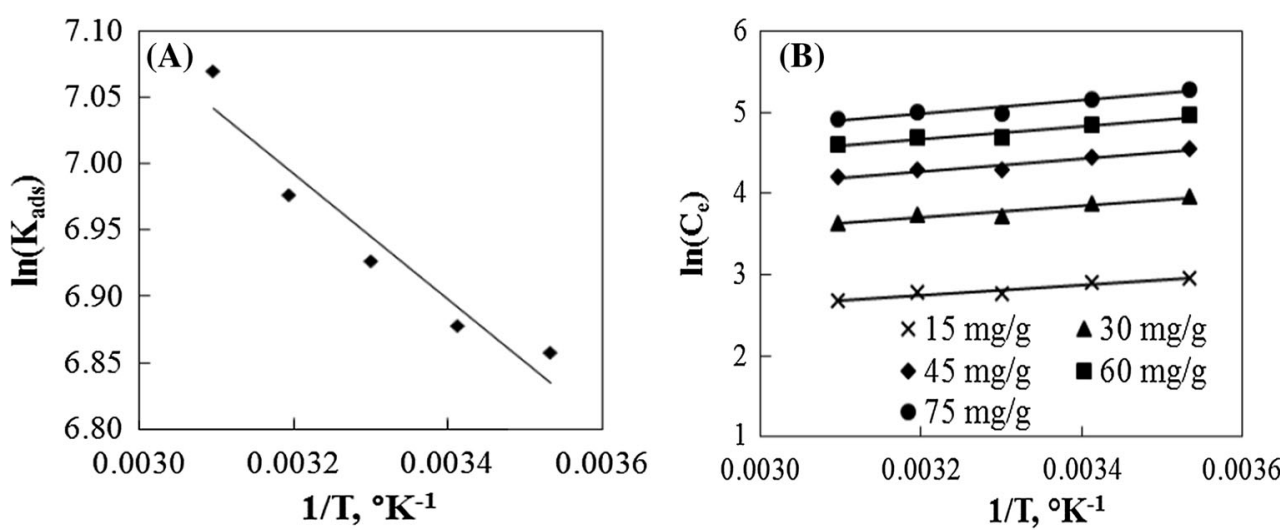

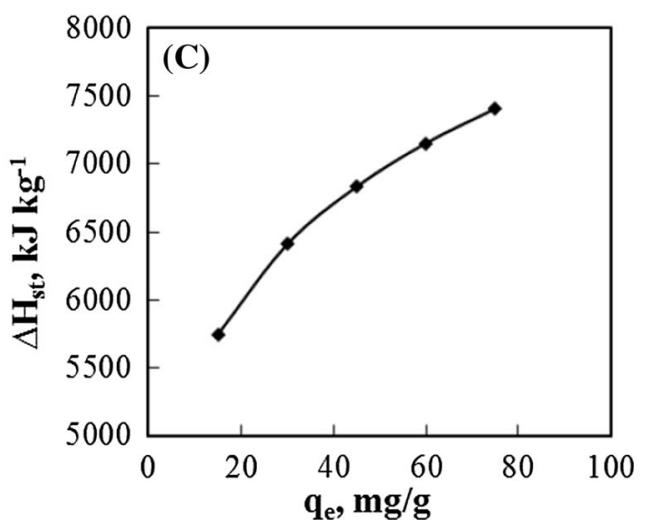


observation, the ACLL provided higher $\mathrm{N}_{2}$-BET surface area of $1131 \mathrm{~m}^{2} \mathrm{~g}^{-1}$ for the aqueous-phase adsorption of $\mathrm{Cr}(\mathrm{VI})$. A positive surface charge at $\mathrm{pH} \leq 5.42$ shows that adsorption of $\mathrm{Cr}(\mathrm{VI})$ onto ACLL would preferably occur in mostly acidic conditions. Based on our experimental analysis, it appears that adsorption of $\mathrm{Cr}(\mathrm{VI})$ would be optimum $\left(13.85 \mathrm{mg} \mathrm{g}^{-1}\right)$ at $\mathrm{pH} 4$ with initial concentration of $100 \mathrm{mg} \mathrm{L}^{-1}$ for an adsorbent dose of $300 \mathrm{mg}$ and contact time of $60 \mathrm{~min}$ at $30^{\circ} \mathrm{C}$. Detailed adsorption kinetic analysis shows that sorption of $\mathrm{Cr}(\mathrm{VI})$ onto the ACLL follows pseudo-second-order kinetic with Redlich-Peterson sorption isotherm having a good agreement with experimental data. Analysis of the thermodynamic parameters for adsorption of $\mathrm{Cr}(\mathrm{VI})$ shows that the overall adsorption process was spontaneous and endothermic. The authors acknowledge that the adsorbent derived from L. leucocephala waste sawdust may not necessarily compete with the commercially available adsorbents. The purpose of this study is to demonstrate the viability of sustainable management of saw dust in a way that is environmentally friendly and yet offers economic incentive, should this material be used for the removal of one of the common carcinogens. The results from this study clearly demonstrate that activated carbon derived from L. leucocephala (ACLL) can be an alternative adsorbent that can be used in a fullscale water and wastewater treatment plant for the removal of $\mathrm{Cr}(\mathrm{VI})$ from contaminated water. To make case for this material, we have thoroughly investigated kinetic, equilibrium and thermodynamic parameters and our results support our initial assertion that ACLL can serve as an alternative to commercially available adsorbents.

While limitations exists in terms of long-term viability and industrial scale production, it should be known that $L$. leucocephala is a drought-tolerant and rapidly growing species of plants that requires no environmental clearance prior to it is being uprooted or being chopped down. Rapid growth, minimal supervision and drought tolerance are the unique properties offered by $L$. leucocephala makes it an ideal candidate for the long-term viability of its production at industrial scale. Regeneration should not be the limitation, because it is common for all the commercially existing adsorbents as well. Given this scenario, the case for $L$. leucocephala rests with the availability of sufficient quality land area that will promote the growth of this plant without competing with other plants that serve as forage for livestock or offer other ecological benefits.

Acknowledgments The authors would like to thank the department of Metallurgical and Materials Engineering at VNIT, Nagpur, for providing access to scanning electron microscopy. The authors also thank to the laboratory assistant from the department of Civil Engineering for help in analysing chromium samples on Atomic Absorption Spectroscopy.

\section{List of symbols}

$\begin{array}{ll}t & \text { Contact time (min) } \\ T & \text { Temperature }(\mathrm{K}) \\ V & \text { Volume of test solution }(\mathrm{mL}) \\ C_{0} & \text { Initial concentration of } \mathrm{Cr}(\mathrm{VI})\left(\mathrm{mg} \mathrm{L}^{-1}\right) \\ C_{\mathrm{e}} & \text { Equilibrium concentration }\left(\mathrm{mg} \mathrm{L}^{-1}\right) \\ m & \text { Adsorbent dose }(\mathrm{mg}) \\ q_{t} & \text { Adsorptive uptake of } \mathrm{Cr}(\mathrm{VI}) \text { at any time } t\left(\mathrm{mg} \mathrm{g}^{-1}\right) \\ q_{\mathrm{e}} & \text { Adsorptive uptake of } \mathrm{Cr}(\mathrm{VI}) \text { at equilibrium } \\ & \left(\mathrm{mg} \mathrm{g}^{-1}\right) \\ q_{\mathrm{m}} & \text { Monolayer adsorptive uptake }\left(\mathrm{mg} \mathrm{g}^{-1}\right) \\ k_{\mathrm{f}} & \text { First-order kinetic coefficient }\left(\mathrm{min}^{-1}\right) \\ k_{\mathrm{S}} & \text { Second-order kinetic coefficient }\left(\mathrm{g} \mathrm{mg}^{-1} \mathrm{~min}^{-1}\right) \\ K_{\mathrm{L}} & \left.\text { Langmuir constant }(\mathrm{L} \mathrm{mg})^{-1}\right) \\ K_{\mathrm{F}} & \text { Freundlich constant }\left(\mathrm{L} \mathrm{mg}^{-1}\right) \\ 1 / n & \text { Heterogeneity factor, dimensionless } \\ B_{1} & \text { Constant in Temkin equation } \\ K_{\mathrm{T}} & \text { Constant in Temkin equation }\left(\mathrm{L} \mathrm{mg}^{-1}\right) \\ a_{\mathrm{R}} & \text { R-P isotherm constant }\left(\mathrm{L} \mathrm{mg}^{-1}\right) \\ K_{\mathrm{R}} & \text { Redlich-Peterson constant }\left(\mathrm{L} \mathrm{mg}^{-1}\right) \\ R & \text { Universal gas constant }\left(\mathrm{J} \mathrm{mol}^{-1} \mathrm{~K}^{-1}\right) \\ R^{2} & \text { Linear correlation coefficient } \\ \Delta G_{\text {ad }}^{\circ} & \text { Gibbs free energy change }\left(\mathrm{kJ} \mathrm{mol}^{-1}\right) \\ \Delta H^{\circ} & \text { Enthalpy change }\left(\mathrm{kJ} \mathrm{mol}{ }^{-1}\right) \\ \Delta S^{\circ} & \text { Entropy change }\left(\mathrm{kJ} \mathrm{mol}^{-1} \mathrm{~K}^{-1}\right)\end{array}$


$\Delta H_{\text {st }} \quad$ Isosteric heat of adsorption $\left(\mathrm{kJ} \mathrm{kg}^{-1}\right)$

$K_{\text {ad }} \quad$ Equilibrium constant for adsorption $\left(\mathrm{L} \mathrm{mg}^{-1}\right)$

\section{Greek letters}

$\alpha \quad$ Initial sorption rate $\left(\mathrm{mg} \mathrm{g}^{-1} \mathrm{~min}^{-1}\right)$

$\beta$ Desorption constant in Elovich equation $\left(\mathrm{g} \mathrm{mg}^{-1}\right)$

$\beta$ Exponent in Redlich-Peterson equation

\section{References}

Atalay E et al (2009) Removal of selected toxic metals by a modified adsorbent. Pract Period Hazard Toxic Radioact Waste Manag 14(2):132-138

Bayramoğlu G, Yakup Arica M (2008) Adsorption of Cr(VI) onto PEI immobilized acrylate-based magnetic beads: isotherms, kinetics and thermodynamics study. Chem Eng J 139(1):20-28

Belay AA (2010) Impacts of chromium from tannery effluent and evaluation of alternative treatment options. J Environ Prot 1(01):53

Chen $\mathrm{S}$ et al (2010) Equilibrium and kinetic adsorption study of the adsorptive removal of $\mathrm{Cr}(\mathrm{VI})$ using modified wheat residue. J Colloid Interface Sci 349(1):256-264

Deng L et al (2009) Biosorption of Cr(VI) from aqueous solutions by nonliving green algae Cladophora albida. Miner Eng 22(4): 372-377

Goswami S, Ghosh UC (2006) Studies on adsorption behaviour of $\mathrm{Cr}(\mathrm{VI})$ onto synthetic hydrous stannic oxide. Water SA 31(4):597-602

Hamadi NK et al (2001) Adsorption kinetics for the removal of chromium(VI) from aqueous solution by adsorbents derived from used tyres and sawdust. Chem Eng J 84(2):95-105

Huang Y et al (2012) Efficient catalytic reduction of hexavalent chromium using palladium nanoparticle-immobilized electrospun polymer nanofibers. ACS Appl Mater Interfaces 4(6): 3054-3061

Jing X et al (2011) Biosorption of Cr(VI) from simulated wastewater using a cationic surfactant modified spent mushroom. Desalination 269(1):120-127

Karthikeyan T et al (2005) Chromium(VI) adsorption from aqueous solution by Hevea brasilinesis sawdust activated carbon. J Hazard Mater 124(1-3):192-199

Kobya M (2004) Removal of Cr(VI) from aqueous solutions by adsorption onto hazelnut shell activated carbon: kinetic and equilibrium studies. Bioresour Technol 91(3):317-321
Kubilay Ş et al (2007) Removal of Cu(II), Zn(II) and Co(II) ions from aqueous solutions by adsorption onto natural bentonite. Adsorption 13(1):41-51

Kumar KV, Kumaran A (2005) Removal of methylene blue by mango seed kernel powder. Biochem Eng J 27(1):83-93

Lataye D et al (2008) Pyridine sorption from aqueous solution by rice husk ash (RHA) and granular activated carbon (GAC): parametric, kinetic, equilibrium and thermodynamic aspects. J Hazard Mater 154(1):858-870

Malkoc E, Nuhoglu Y (2007) Determination of kinetic and equilibrium parameters of the batch adsorption of $\mathrm{Cr}(\mathrm{VI})$ onto waste acorn of Quercus ithaburensis. Chem Eng Process 46(10):1020-1029

Malwade KR, Ramirez D, Kurwadkar S (2015) A comparative study of the aqueous-phase adsorption of sulfamethazine onto commercially available and laboratory developed activated carbon. Emerg Micro-Pollut Environ Occur Fate Distrib Am Chem Soc 1198:113-131

Mohammod $\mathrm{M}$ et al (2011) Removal of $\mathrm{Zn}^{2+}$ from aqueous solution using castor seed hull. Water Air Soil Pollut 215(1-4):609-620

Montazer-Rahmati MM et al (2011) Kinetics and equilibrium studies on biosorption of cadmium, lead, and nickel ions from aqueous solutions by intact and chemically modified brown algae. J Hazard Mater 185(1):401-407

Namasivayam C, Yamuna R (1995) Adsorption of chromium(VI) by a low-cost adsorbent: biogas residual slurry. Chemosphere 30(3): $561-578$

Órfão J et al (2006) Adsorption of a reactive dye on chemically modified activated carbons-influence of $\mathrm{pH}$. J Colloid Interface Sci 296(2):480-489

Putra EK et al (2009) Performance of activated carbon and bentonite for adsorption of amoxicillin from wastewater: mechanisms, isotherms and kinetics. Water Res 43(9):2419-2430

Qaiser S et al (2009) Biosorption of lead(II) and chromium(VI) on groundnut hull: equilibrium, kinetics and thermodynamics study. Electron J Biotechnol 12(4):3-4

Rao Popuri S et al (2007) Biosorption of hexavalent chromium using tamarind (Tamarindus indica) fruit shell-a comparative study. Electron J Biotechnol 10(3):358-367

Srivastava S, Goyal P (2010) Novel biomaterials: decontamination of toxic metals from wastewater. Springer Science \& Business Media, Springer Berlin Heidelberg

Suzuki M (1990) Adsorption engineering. Elsevier Science Publishing Company Inc., New York

Tailor R et al (2012) Sorptive removal of phenol by zeolitic bagasse fly ash: equilibrium, kinetics, and column studies. J Chem Eng Data 57(5):1437-1448

Tan IAW et al (2009) Adsorption isotherms, kinetics, thermodynamics and desorption studies of 2,4,6-trichlorophenol on oil palm empty fruit bunch-based activated carbon. J Hazard Mater 164(2-3):473-482 
USEPA (2010) Toxicological review of hexavalent chromium. EPA/ 635/R-10/004C

Vinodhini V, Das N (2009) Mechanism of Cr(VI) biosorption by neem sawdust. Am Eurasian J Sci Res 4(4):324-329
Wang Y et al (2006) Isotherms, kinetics and thermodynamics of dye biosorption by anaerobic sludge. Sep Purif Technol 50(1):1-7

Wang XS et al (2009) Removal of chromium(VI) from aqueous solution using walnut hull. J Environ Manag 90(2):721-729 